\title{
Whistles of Bottlenose Dolphins (Tursiops truncatus) in the Sado Estuary, Portugal: Characteristics, Production Rates, and Long-Term Contour Stability
}

\author{
Manuel E. dos Santos, ${ }^{1,2}$ Sónia Louro, ${ }^{1}$ Miguel Couchinho, ${ }^{2}$ and Cristina Brito ${ }^{2}$ \\ ${ }^{1}$ Unidade de Investigação em Eco-Etologia, Instituto Superior de Psicologia Aplicada, \\ Rua Jardim do Tabaco 34, 1149-041 Lisboa, Portugal \\ ${ }^{2}$ Projecto Delfim - Portuguese Center for the Study of Marine Mammals, Apartado 23051, 1147-601 Lisboa, Portugal
}

\begin{abstract}
This study focuses on the whistle characteristics and production patterns of bottlenose dolphins (Tursiops truncatus) resident in the Sado Estuary, Portugal. Recordings and observations were conducted inside the estuary and in adjacent coastal waters using single hydrophones between 1987 and 2000. In the groups sampled, the mean number of whistles emitted per minute per animal was 0.28 . The acoustic characteristics of a sample of 735 whistles were measured and compared with data from other Tursiops populations, showing that, in a pattern of overall similarity, the whistles recorded in the Sado are relatively long and the frequency range used is relatively wide. Mean peak frequency was $9.2 \mathrm{kHz}$. About $30 \%$ of the whistles were stereotyped, and remarkable stability was found in several contours over a 12-year period. No relation was found between dolphin group size and whistle rate, suggesting some restriction in production; and no relation was found between dolphin group size and the emission of different contours. Significant variation was found between episodes of simple travel and more aroused activities in terms of the production of whistles in general and also of different whistle contours.
\end{abstract}

Key Words: whistles, acoustic production, bottlenose dolphin, Tursiops truncatus, activity patterns, Sado Estuary

\section{Introduction}

The abundance and variety of the underwater sounds produced by dolphins reflect their important role in the ecology and social life of these marine mammals and is of great interest for our understanding of animal communication. The acoustic signals of dolphins may be pulsed or unpulsed and may have a social and/or echolocation function (see reviews by Herman \& Tavolga, 1980; Popper, 1980). In the context of the acoustic repertoire of dolphins, the term whistle refers to unpulsed, narrow-band signals, lasting between 0.1 and $4 \mathrm{sec}$. The acoustic frequency of whistles may be constant in some cases, but more commonly these sounds are frequency-modulated, showing distinct "contours," with dominant frequencies usually between 5 and $14 \mathrm{kHz}$ (e.g., Caldwell et al., 1990).

Caldwell \& Caldwell (1965) interpreted the fact that each animal seems to emit a predominant stereotyped whistle as an acoustical signature to be a statement of identity and location. This hypothesis has been developed in many studies (e.g., Caldwell et al., 1990; Sayigh et al., 1990, 1998; Janik et al., 1994; Tyack, 1997; Janik \& Slater, 1998; Janik, 2000; Fripp et al., 2005). Other possible functions of whistle stereotypes have been proposed, namely that groups may share a similar contour (e.g., McCowan \& Reiss, 1995) or that groups of dolphins may adopt similar whistles by convergence (see also Smolker \& Pepper, 1999).

In a study of coastal bottlenose dolphins (Tursiops truncatus) from different populations in the North Carolina and Florida coastal waters, Jones \& Sayigh (2002) found significant variations in the vocal emission rates, probably related to local conditions and to the social and behavioural context. Generally, whistling increased with dolphin group size and was especially common in social interactions.

Cook et al. (2004) also recently reported that whistle rates increase with group size in the Sarasota, Florida, bottlenose dolphin population and that whistles were more frequent in socializing episodes than in traveling. Acevedo-Gutiérrez \& Stienessen (2004) studied the whistles of bottlenose dolphins in Costa Rica and, in a different perspective, proposed that group size increased with the whistling of feeding animals, especially when competing silky sharks were present.

A small, resident population of bottlenose dolphins has been the focus of a number of studies in the Sado Estuary and adjacent coastal waters (e.g., dos Santos \& Lacerda, 1987; dos Santos et al., 1996; 
Harzen, 1998, 2002; Gaspar, 2003). On a year-round, daily basis, groups of these animals enter the river mouth and forage, play, and socialize, mostly in the quieter, cleaner areas of the estuary. The population size is now about 30 , and the analysis of long-term demographic parameters showed that survival rates are lower than those observed in other populations (Gaspar, 2003). Analysis of underwater signals emitted by these dolphins revealed the usual repertoire of pulsed sounds (click trains, moans, squawks, squeaks, bangs, and the curious bray series) and also abundant whistles (dos Santos et al., 1990, 1995).

This study aims to describe the whistle repertoire of these resident dolphins, to compare their basic acoustic characteristics with data available from other populations, and to analyze the whistle production rates according to dolphin group size and activity. Questions of interest were whether whistle production increased with group size in the various activity contexts, and whether the number of different contours increased with group size. It was expected that whistling would be more abundant in those activities involving higher arousal levels (i.e., when animals show rapid, excited aerial behaviours).

\section{Materials and Methods}

\section{Study Area}

The Sado Estuary is located on the Western continental coast of Portugal (the approximate position of the river mouth is $38^{\circ} 29^{\prime} \mathrm{N}, 8^{\circ} 55^{\prime} \mathrm{W}$; see map in dos Santos \& Lacerda, 1987). The estuary is bordered on the north side by the city of Setúbal and its harbour and industrial zones and on the south side by the Peninsula of Tróia, mainly used for tourism and recreational activities. The lower estuary is divided into two channels by sand and mud banks. The south channel is wider, deeper, and shows a more intense water flow than the north channel, which receives most urban and industrial effluent discharges. Previous data show that dolphins spend more time feeding in the south channel than in other areas of the estuary (e.g., dos Santos et al., 2001). Maximum depths are $40 \mathrm{~m}$ at the mouth, $25 \mathrm{~m}$ in the south channel, and $15 \mathrm{~m}$ in the north channel. The upper part of the estuary, upstream from the channels, is very shallow (below $4 \mathrm{~m}$ ), with extensive mud flats.

\section{Sampling}

The bottlenose dolphin groups were monitored during 110 small-boat surveys between 1987 and 2000 , with an average duration of $6.2 \mathrm{~h}$. Leaving the harbour, a predefined course was followed until a group of dolphins was sighted. A group was considered to include all animals engaged in the same general activity within an approximate 200 -m radius. A non-intrusive approach was adopted in all surveys, keeping a distance of 50 to $100 \mathrm{~m}$ between the boat and the dolphins. In each survey, the first recording sample was collected at least half an hour after the initial sighting to allow the dolphins time to habituate to our presence. Behaviour and acoustic samples of a focal group were recorded with the engine stopped. By norm, each sampling period lasted for 5 min of observation and continuous recording. In some cases, shorter sampling periods (of over $1 \mathrm{~min}$ ) were used-for example, if the dolphins' activity changed while recording or if they moved away, in which case we followed, keeping the same distance. A lag period of 30 min was kept between samples for independence. If during the lag periods there was not a change in group composition or activity, we moved to approach a different focal group. Also, to avoid recording whistles from outside the focal group, sampling was aborted if other groups approached to less than approximately $1,000 \mathrm{~m}$.

Ad libitum and "group follow" were used as behavioural sampling methods (Altmann, 1974; Mann, 1999). For each sample, the focal group's position, size, and activity were recorded and photographs were taken. Group size was determined by direct counting of the animals by two observers and by averaging the counts. If counts differed by more than five, group size for that sample was considered "indeterminate."

In this estuary, water visibility is usually limited to less than $250 \mathrm{~cm}$ (using a Secchi disk), so it is quite difficult to observe underwater behaviours, recognize individuals below the surface, or determine sex.

Four activity categories were recognized in the field, which were valid when all individuals were performing similar behaviours as observed at the surface: (1) Travel - rapid, linear displacement of a tight group moving between areas, with no aerial behaviours; (2) Travel/Feeding - zigzag displacement of a subdivided group, with dives longer than $1 \mathrm{~min}$ and occasional aerial activity or fish chase; (3) Feeding - individual animals, dyads, or tryads surfacing more than $10 \mathrm{~m}$ apart, with only very short dives and abundant movements at the surface, including captures, prey leaping, or prey toss; and (4) Socializing - dyads or tryads showing excited surface and aerial behaviours, with physical contacts and no prey detectable, sometimes with synchronous movements.

For acoustic sampling, which was simultaneous with behaviour sampling, signals were recorded on one channel while commentary was recorded on a second channel. The more detailed recorded descriptions of behaviour and events were later compared with the commentary on the acoustic tapes. Different equipment items were available over the years. Signals were recorded using Brüel \& Kjær hydrophones, models 8101, 8103 (with B\&K 2646 pre-amplifier), and 8104 (with B\&K 2635 
pre-amplifier). A Nagra IV-SJ reel-to-reel analog recorder was used in earlier recordings, with a tape speed of $19 \mathrm{~cm} / \mathrm{s}$, which was replaced in 1992 by a Sony TCD-D10 Pro digital recorder. All combinations had a flat frequency between $20 \mathrm{~Hz}$ and $20 \mathrm{kHz}$ (analog recordings) or $22 \mathrm{kHz}$ (digital recordings).

\section{Data Analysis}

Fifty hours of underwater signals were collected on reel-to-reel magnetic tapes or on DAT tapes. In the laboratory, time and frequency analyses of the underwater sound samples were made, using mostly the software Canary, Version 1.2.4 (Charif et al., 1995). To facilitate the visual comparison of frequency contours, a 2-sec file was created for each whistle, and sonograms were printed (more than once if there was more than one whistle in that file). For the analysis of the abundance of signal production, emission rates were calculated, dividing the number of whistles counted by the number of minutes recorded and the number of animals in the focal group.

To categorize dolphin whistles, visual classification of sonograms by various observers is reportedly more reliable than mathematically based procedures (Janik, 1999). Therefore, the classification of whistles in this study was made through visual inspection of the sonograms by each author separately. Classifications were later pooled, and discordant cases were removed from the sample of recognized contours. Categories were created, grouping contours that could be repeatedly recognized in multiple occurrences (i.e., defined as stereotyped contours), while the remaining whistles were considered "nonstereotyped." These latter whistles were withdrawn from the study of contours and contour occurrence, although they were counted for the analysis of whistle emission rates.

For the quantitative acoustical analysis of the whistles, the following measurements were made using Canary's tools: initial, final, maximum, minimum, and peak frequency; duration; and frequency modulation range. Due to our upper-frequency limitations, harmonic bands were not considered, and only the fundamental was measured.
Nonparametric statistical procedures were adopted, using the statistical package SPSS, Version 11.0.0 (SPSS, Inc., 2001) for most analyses. The Kruskal-Wallis ANOVA and the Dunn post-hoc test of multiple comparisons (Zar, 1996) were used to analyze differences in whistle production rates among the various activities. The Spearman rank correlation coefficient was calculated to compare whistle abundance and group size. A repeated-measures $t$-test was used to compare initial and final whistle frequencies.

\section{Results}

Characterization of the Whistles

For the measurement of the acoustic characteristics of this population's repertoire, 735 whistles with the best signal-to-noise ratio were selected from the sample of stereotyped whistles. The data are summarized in Table 1. For comparison, acoustic measurements of whistles from published studies on Tursiops populations are summarized in Table 2 .

A noticeable feature of this whistle sample was the fact that frequencies rise from initial to final, with a mean increase of $6.3 \mathrm{kHz}(\mathrm{SD}=4.84)$. This difference between initial and final frequencies is significant, as evaluated by a $t$-test $(t=-35.35$, $\mathrm{DF}=734, p<0.001$, two-tailed).

\section{Whistle Abundance}

A set of 285 acoustical and behavioural recording samples was analyzed, with a mean duration of

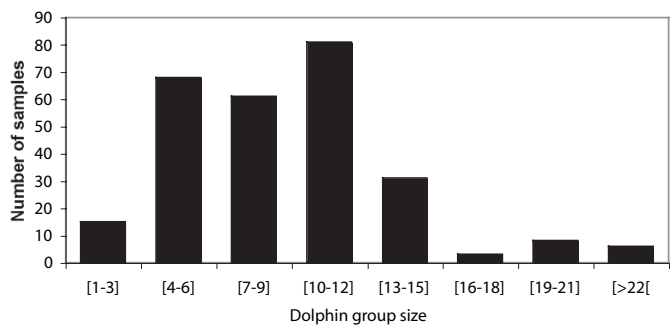

Figure 1. Distribution of bottlenose dolphin group size for 273 recording samples in the Sado Estuary, Portugal

Table 1. Summary statistics of the main acoustical measures of the bottlenose dolphin whistles sampled in the Sado Estuary, Portugal $(n=735)$

\begin{tabular}{lrrrr}
\hline Measures & $\overline{\mathrm{x}}$ & SD & Minimum & Maximum \\
\hline Initial frequency $(\mathrm{kHz})$ & 5.8 & 1.8 & 2.0 & 15.3 \\
Final frequency $(\mathrm{kHz})$ & 12.1 & 4.4 & 2.2 & 21.0 \\
Maximum frequency $(\mathrm{kHz})$ & 15.0 & 2.7 & 7.9 & 21.0 \\
Minimum frequency (kHz) & 5.4 & 1.2 & 2.0 & 9.0 \\
Peak frequency $(\mathrm{kHz})$ & 9.2 & 2.6 & 3.5 & 20.4 \\
Duration $(\mathrm{ms})$ & 859 & 396 & 257 & 4,130 \\
\hline
\end{tabular}


Table 2. Whistle measurement averages from some bottlenose dolphin populations; frequencies are in $\mathrm{kHz}$, and durations are in seconds.

\begin{tabular}{lccccc}
\hline Location & $\begin{array}{c}\text { Minimum } \\
\text { frequency }\end{array}$ & $\begin{array}{c}\text { Maximum } \\
\text { frequency }\end{array}$ & $\begin{array}{c}\text { Frequency } \\
\text { range }\end{array}$ & Duration & Reference \\
\hline Sado Estuary, Portugal & 5.40 & 15.00 & 9.60 & 0.86 & Present study \\
Isla del Coco, Costa Rica & 7.51 & 12.41 & 4.90 & 0.38 & $\begin{array}{c}\text { Acevedo-Gutiérrez \& } \\
\text { Stienessen, 2004 }\end{array}$ \\
Moreton Bay, Australia & 8.51 & 13.96 & 5.46 & 0.66 & Ong, 1996 \\
& 4.32 & 10.76 & 6.44 & 0.34 & (T. aduncus) \\
Galveston Bay, TX & & & & 0.75 & Wang et al., 1995 \\
Corpus Christi Bay, TX & 5.98 & 11.95 & 5.97 & 0.69 & Wang et al., 1995 \\
South Padre Island, TX & 5.88 & 11.43 & 5.55 & 0.60 & Wang et al., 1995 \\
Golfo San José, Argentina & 5.91 & 10.33 & 4.96 & 7.14 & Wang et al., 1995 \\
Gulf of California, Mexico & 6.91 & 13.65 & 6.77 & 0.66 & Wang et al., 1995 \\
Shark Bay, Australia & 3.57 & 10.57 & 7.00 & 0.68 & Wang et al., 1995 \\
& & & & & (Tursiops sp.) \\
Taiji, Japan & 7.37 & 11.62 & 4.25 & 0.62 & Wang et al., 1995 \\
Captives, mostly & 4.26 & 14.98 & 10.66 & 0.95 & Calculated from data of \\
from Florida & & 16.24 & 8.91 & 1.30 & Caldwell et al., 1990 \\
Western North Atlantic & 7.33 & & & Steiner, 1981 \\
\hline
\end{tabular}

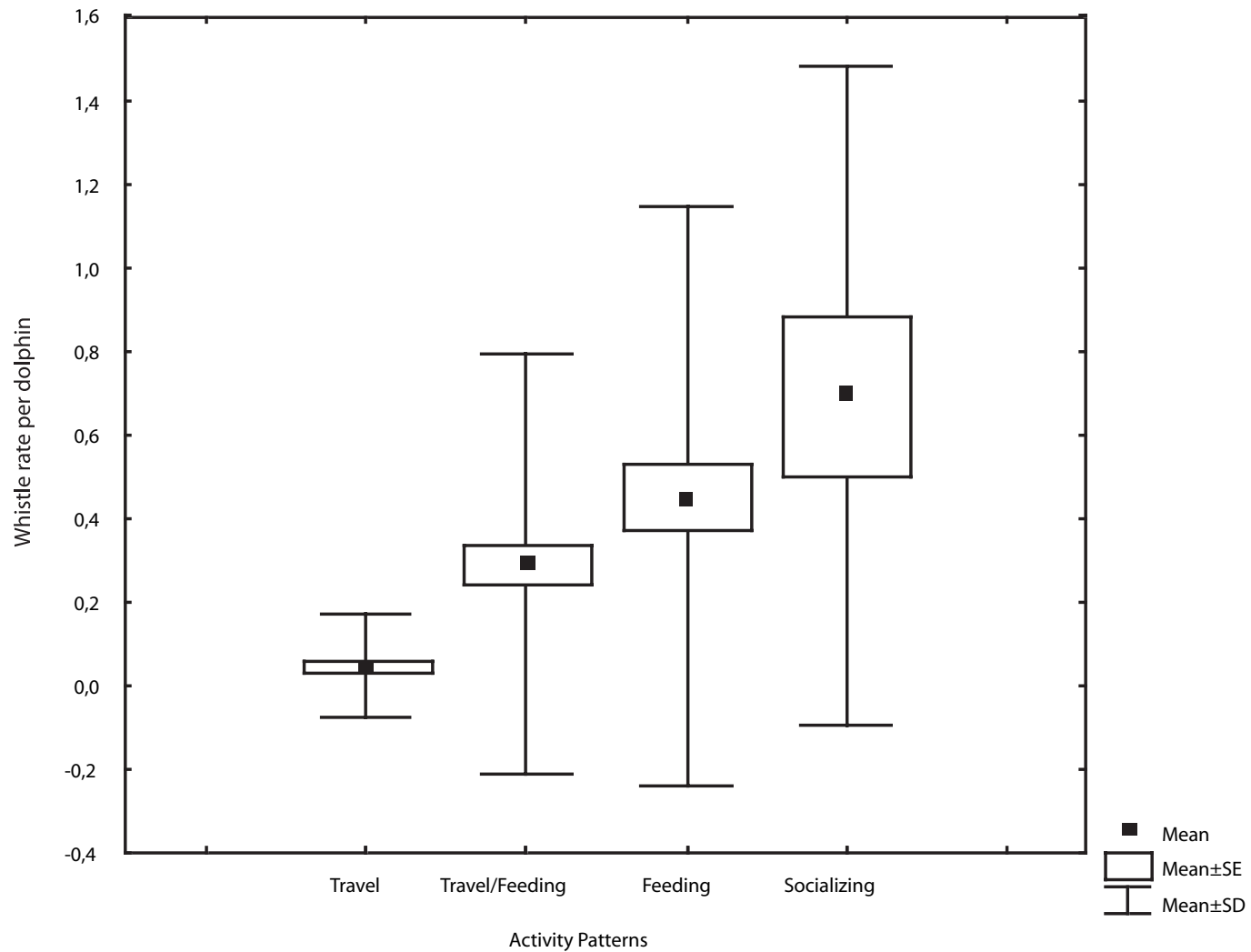

Figure 2. Number of whistles per min per animal in the four activity patterns identified for bottlenose dolphins in the Sado Estuary, Portugal 
$4.12 \min (\mathrm{SD}=2.47)$. Dolphin group size distribution in 273 of these (samples with indeterminate group sizes were removed) is shown in Figure 1.
A positive relation was expected between the number of dolphins in each group and the number of whistles per min in that sample; however, no

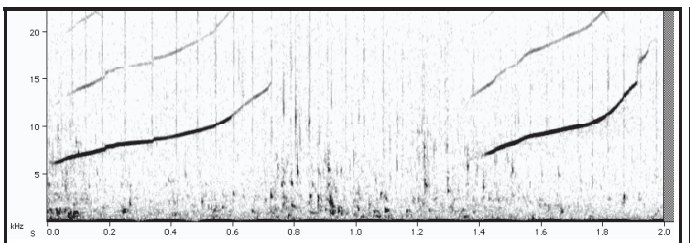

US, recorded 25 September 1992

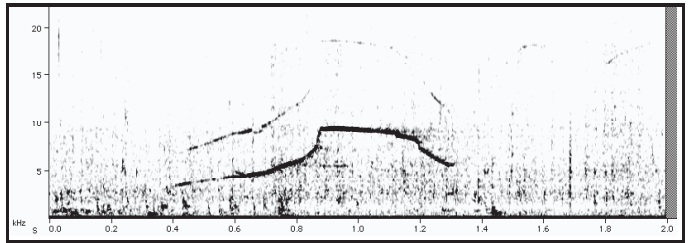

KE, recorded 7 October 1992

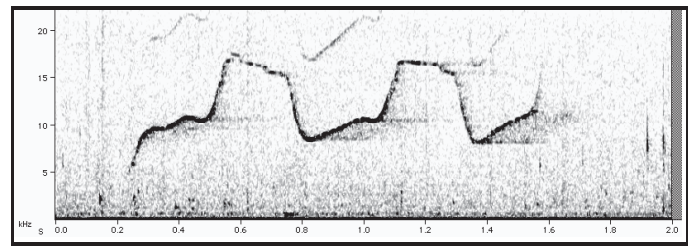

AZ, recorded 7 October 1992

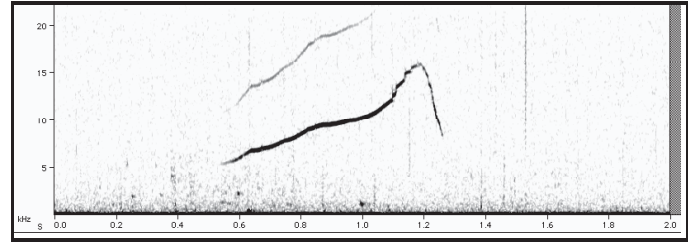

AP, recorded 25 September 1992

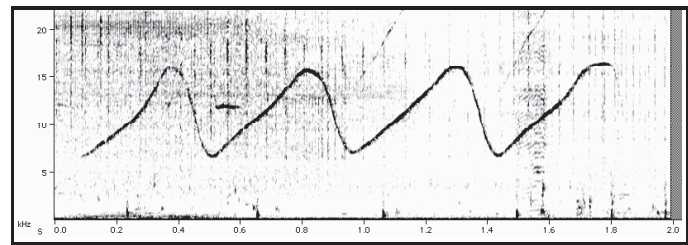

CM, recorded 7 October 1992

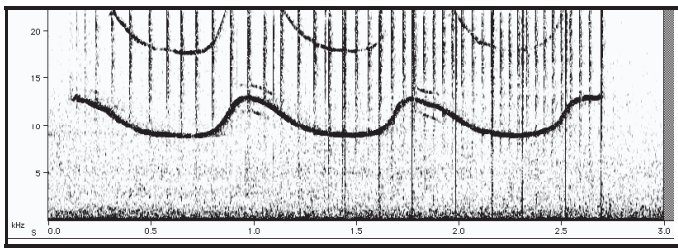

MC, recorded 7 October 1992

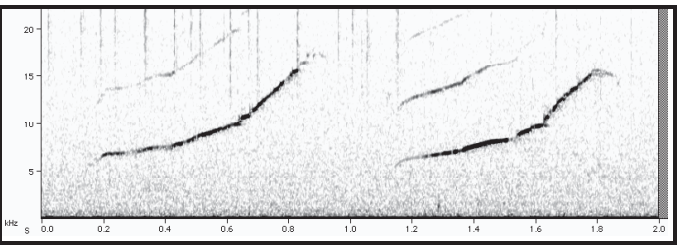

US, recorded 1 July 1999

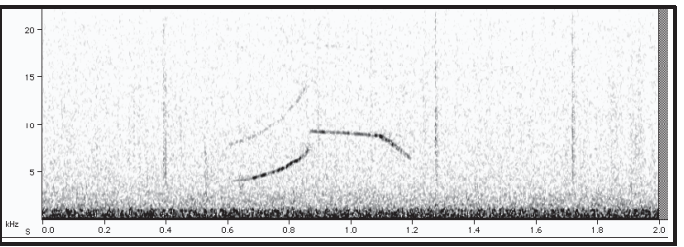

KE, recorded 8 July 1999

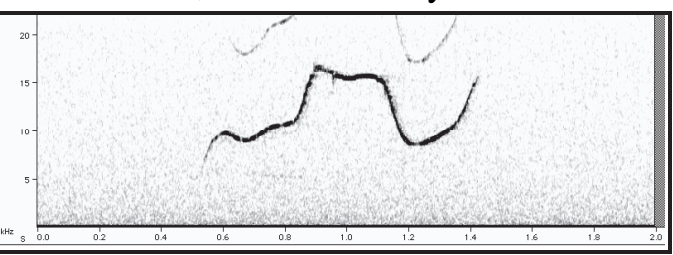

AZ, recorded 8 July 1999

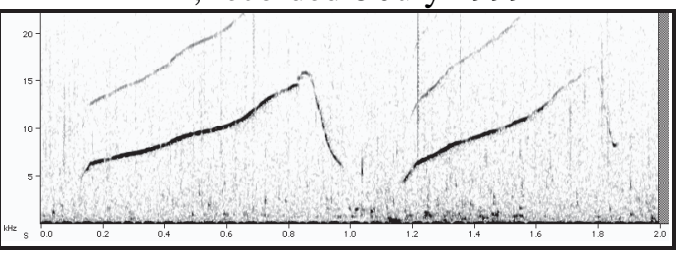

AP, recorded 22 June 1999

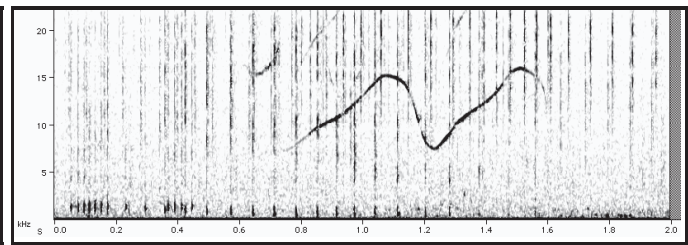

CM, recorded 24 September 1999

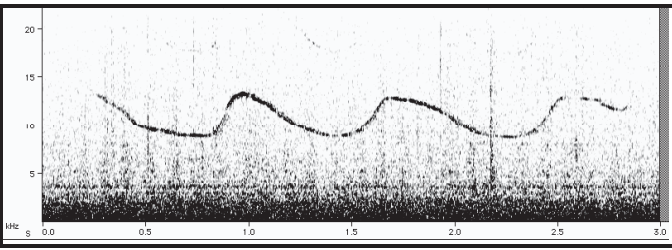

MC, recorded 13 October 1999

Figure 3. Sonograms of six pairs of stereotypical bottlenose dolphin whistles, recorded at an approximately 7-year interval in the Sado Estuary, Portugal 
significant correlation was found $(\mathrm{r}=-0.051 ; p>$ $0.1 ; n=273$ ).

The calculation of whistle production rate resulted in a mean number of whistles per min per animal of $0.28(\mathrm{SD}=0.54, n=273)$ in all activities. In surface feeding, the mean number of whistles per min per dolphin was $0.45(\mathrm{SD}=1.64$, $n=76$ ), and it should be noted that four of these samples had zero whistles. During Socializing, the mean whistling rate ascended to $0.69(\mathrm{SD}=0.79$, $n=17$ ), with three samples having zero whistles. Figure 2 shows the mean numbers of whistles per min per dolphin separated by activity pattern. Analysis of variance indicated a significant difference in whistle rates among activity patterns:
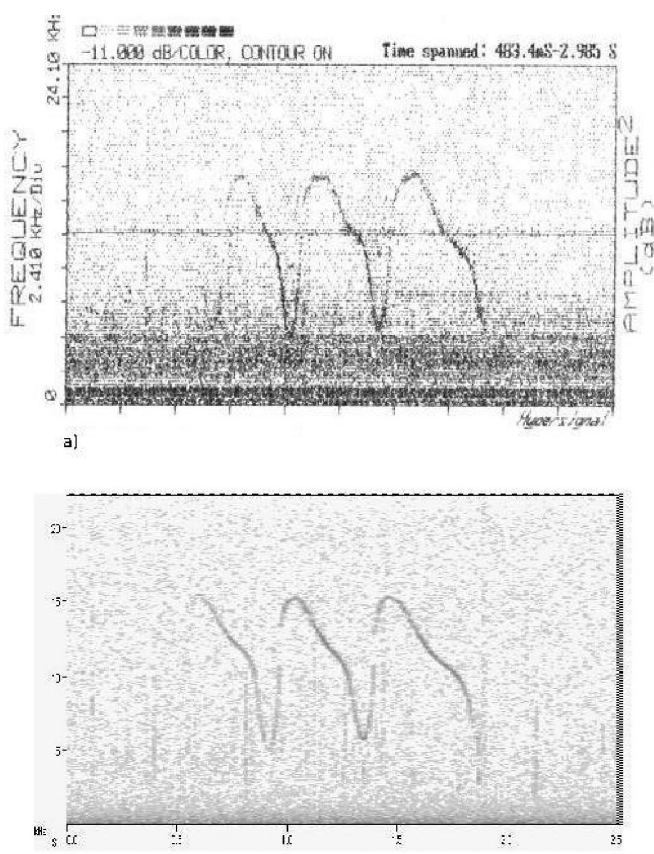

b]

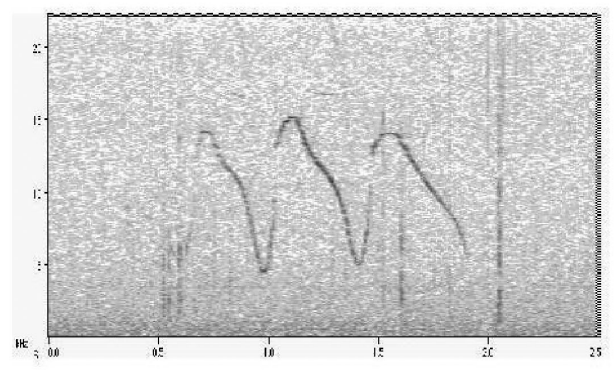

c)

Figure 4. Sonograms of bottlenose dolphin whistles recorded in the Sado Estuary, Portugal, in (a) 1987, (b) 1992, and (c) 1999, illustrating the stability of the CA3 contour category over a 12 -year period
$\mathrm{H}_{(3,273)}=40.82 ; p<0.001$. With the Dunn posthoc test, differences specifically between Travel and all other activity patterns were found $(p<$ 0.001 in all three cases). Correlations between whistle rates and group size in each of the activity pattern categories were nonsignificant.

\section{Identification of Stereotyped Frequency-Modulation Contours}

Of the whistles recorded and counted for the abundance analysis, about $30 \%$ were clear and stereotyped. For example, from the recordings of 1992, 1993, 1995, 1999, and 2000 (3,393 whistles), 971 were defined as stereotyped. A total of 26 different categories of stereotyped contours was created. Fifteen different categories of stereotyped contours were detected in more than two years, showing remarkable structural stability. Figure 3 shows, as examples, six pairs of whistles recorded in 1992 and again in 1999 to illustrate their stability over a 7-year period. Some contours maintained their time and frequency characteristics for even longer periods. Such an example is presented in Figure 4, with sonograms of whistles recorded in 1987, 1992, and 1999.

\section{Occurrence of Contours}

A positive relation between dolphin group size and whistle contour variability also was expected. Again, the correlation coefficient was calculated for group size, and the number of different contours in each sample was not significant $(\mathrm{r}=0.113$, $p>0.05, n=145$ ).

To explore the possible effects of the various activities, Figure 5 shows the mean number of different contours per min per dolphin, according to activity patterns. The analysis of variance reveals a significant difference among the activity patterns: $\mathrm{H}_{(3,145)}=11.86, p<0.01$. With the Dunn post-hoc test, differences were found specifically between Travel and Feeding $(p<0.005)$ - the most contrasting activity pair of patterns in terms of the occurrence of different contours.

\section{Discussion}

As part of the ongoing effort to investigate the underwater acoustic emissions of the bottlenose dolphins resident in the Sado Estuary, this study focused on the characteristics of their whistles and their production patterns. A quantitative description of a sample of stereotyped whistles is presented and may be compared to published data from other Tursiops populations. In a pattern of overall acoustic similarity, the whistles recorded in the Sado region are relatively long (only three of 12 other populations showed higher average duration), and the frequency range was wider than in all other wild populations mentioned. It may be relevant, as 


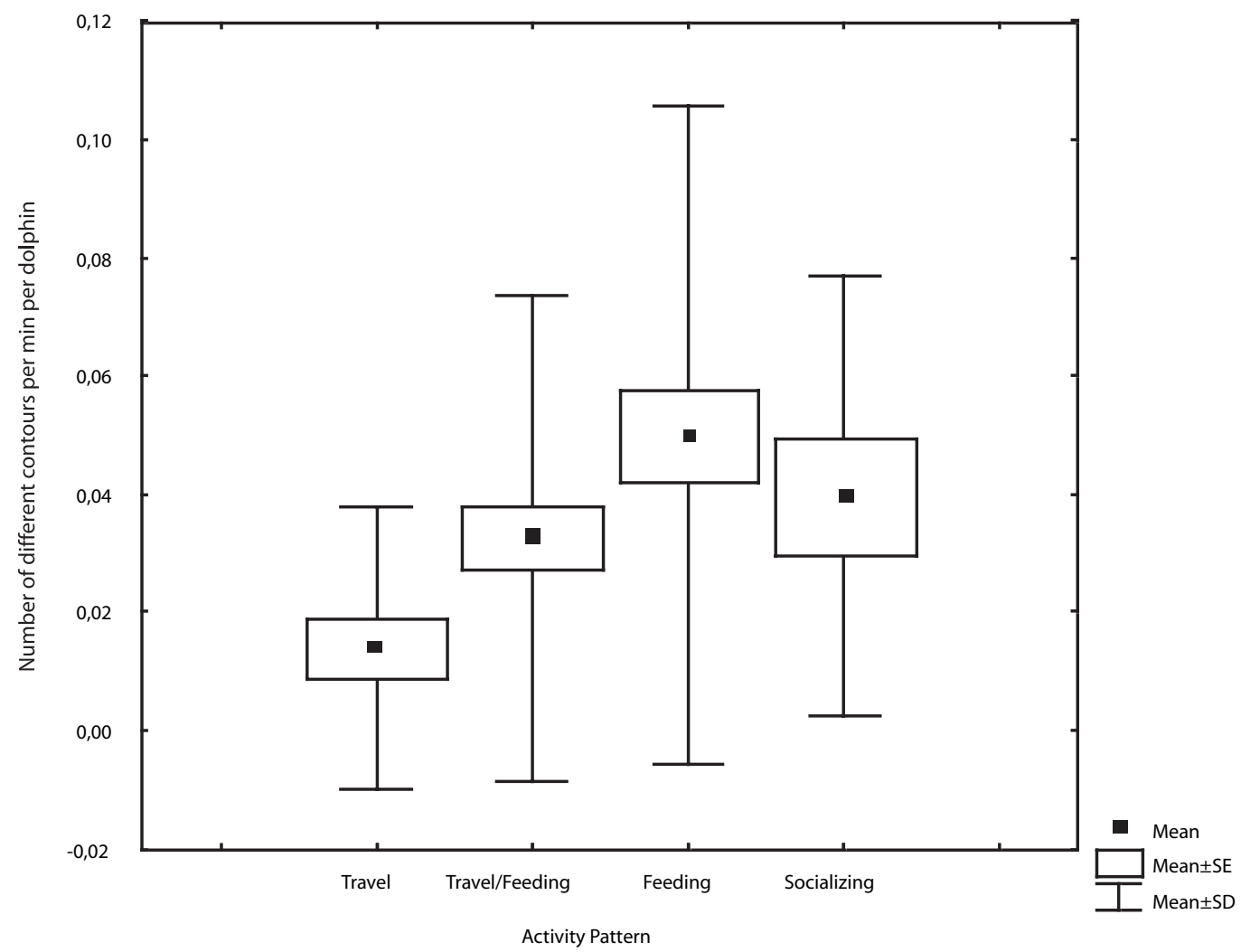

Figure 5. Number of different whistle contours per min per dolphin in the four activity patterns identified in recordings of bottlenose dolphins in the Sado Estuary, Portugal

noted by Caldwell et al. (1990), that longer whistles are easier to locate than shorter tones.

Some local environmental factors, such as high ambient noise, may influence the acoustic characteristics of whistles in some populations of dolphins, as suggested by Wang et al. (1995). The mean value of peak frequencies obtained from our sample $(9.2 \mathrm{kHz})$ was well above the typical spectra of low-frequency underwater ambient noise in the area, mainly of naval and industrial origin (dos Santos et al., 1996; Ferreira et al., 1996). No relation can be presently established, and future studies should focus on this issue.

A pattern of the whistles from the Sado Estuary dolphin population is a general increase in frequency in contrast with the more balanced or even descending contours found in other repertoires (e.g., Steiner, 1981; Wang et al., 1995). This topic also invites further research since the biological, or possibly cultural, significance or basis of this characteristic is not understood at present.

Studies show that dolphin group size has a positive relation with whistle production (Jones \& Sayigh, 2002; Cook et al., 2004). From our data, however, correlations between the number of dolphins and the whistle rates calculated for each sample were null and nonsignificant. If more dolphins are not producing more whistles, neither in general nor in any of the activities sampled, then there might be some social restriction mechanism limiting emissions. If, indeed, too many whistles were produced simultaneously in a group, perception, recognition, and appropriate response might be hindered by the confusion caused by excessive overlaps or information overload, especially in a noisy environment.

The whistle emission rate found in this sample set, although quite variable, showed a mean of 0.28 whistles per min per dolphin. Adjusting the data presented by Jones \& Sayigh (2002), it is clear that their rates are on the same order of magnitude. Acevedo-Gutiérrez \& Stienessen (2004) obtained similar whistling rates for "non-feeding" dolphins (0.4) in Costa Rica. "Feeding" dolphins, on the other hand, emitted whistles at the higher rate of 2.7 per min per dolphin, sometimes in the presence of competing sharks. 
In captivity, during experimental tests, two studies also obtained much higher rates: Tyack (1986) counted 7.6 and 4.5 whistles/min for two dolphins, respectively; and Janik et al. (1994) calculated 8.1, 8.4, and 12.7 whistles/min from one single dolphin in three different situations. These values were obtained in sessions that were special times for the animals, with staff and activities around the pools, and may be typical of high excitement contexts.

Activity and whistle abundance are often related (Jones \& Sayigh, 2002; Acevedo-Gutiérrez \& Stienessen, 2004; Cook et al., 2004). Traveling dolphins were quieter in general, and whistling rates increased, especially in those activities involving excited predation or socializing. This pattern, noted in the early descriptions of Wood (1953), remains a solid fact: regardless of group size, whistling density is associated with excitement or arousal.

Additionally, significant variation was found in the number of different stereotyped contours recorded in contexts of low or high arousal levels, particularly between travel and feeding episodes, also regardless of group size. In other words, when dolphins are more excited, especially in feeding episodes, the richness and variability in their whistle production increased. This fact does not seem to be an effect of group size. More contours were in fact emitted but not because more animals were present. The ecological and social contexts of these episodes are certainly more complex than those of simple travel, and motivational states were more dynamic and varied. That may be the reason why groups produced whistles with a higher diversity of contours, both stereotyped and nonstereotyped.

On the other hand, there may be more advantages in quiet traveling, especially when groups pass through the narrow river mouth or move between areas separated by banks. Formations are tight; there is little need for short-range acoustic communication; and attentive, passive audition might facilitate detection of boats, other dolphin groups, or even potential prey patches (dos Santos \& Almada, 2004).

Only about $30 \%$ of the whistles analyzed in this study presented stereotyped contours. Even though an acoustic signature might constitute the main function of the stereotyped whistles, there is a great deal of variability in the repertoire that has not been examined, which is a common problem already noted by McCowan \& Reiss (1995). Furthermore, even within each contour type, it is unknown whether the variations in stereotyped whistles reflect individual variability or the emission by different animals. It is of course of great interest to understand how context or activity affect the properties of the stereotyped whistles (see Caldwell et al., 1990) and how variations could be related to motivational states or other useful communicative functions. There is also the possibility that near-identical contours could be approximations to shared whistles produced by different individuals (Smolker \& Pepper, 1999) or the result of whistle matching (Janik, 2000).

An interesting result of this study is the longterm stability in whistle contours up to 12 years. Similar frequency-modulation stability in freeranging dolphins has been reported so far only by Sayigh et al. (1990). In captive bottlenose dolphins, Caldwell et al. (1990) also found long-term contour stability up to 18 years. Any sort of signature function or other specific meaning would of course be promoted by long-term stability in whistles commonly used in the population, perhaps even across generations.

In summary, the data presented contribute to the comparative study of the whistle acoustic characteristics and production patterns in wild populations of bottlenose dolphins. No relation was found between group size and the production of whistles, but behavioural states were related to the number of whistles and also to the variability of contours. Stereotyped whistles, as in other populations, were recognizable, with little change throughout the years. Clearly, the functions of whistles still require much research effort, both in naturalistic settings with techniques for emitter identification and also in more controlled settings. This remains a challenging area of dolphin bioacoustics and behavioural biology.

\section{Acknowledgments}

We gratefully acknowledge financial support by the sponsors of Projecto Delfim, especially Portucel and Mundo Aquático-Zoomarine, and also the Prize "Milénio Sagres Expresso 2001." ISPA is funded by the Portuguese Foundation for Science and Technology (FCT). This research has received logistical support from Club Naval Setubalense, the Technical University of Lisbon (CAPS-IST), and the Sado Estuary Marine Reserve (RNES). Several colleagues and many volunteers participated in the field work and lab analyses in different phases of the project. We are especially grateful to Vítor Almada, J. Bento-Coelho, Giorgio Caporin, António José Ferreira, David Gonçalves, H. Onofre, and Rafael Serrenho. Sue Cosens provided helpful comments to an earlier version of the manuscript. We are also indebted to Jeanette Thomas, Sarah Stienessen, and Deborah Fripp for their careful reviews. 


\section{Literature Cited}

Acevedo-Gutiérrez, A., \& Stienessen, S. (2004). Bottlenose dolphins (Tursiops truncatus) increase number of whistles when feeding. Aquatic Mammals, 30(3), 357362. (DOI 10.578/AM.30.3.2004.357)

Altmann, J. (1974). Observational study of behaviour: Sampling methods. Behaviour, 49, 227-267.

Caldwell, M. C., \& Caldwell, D. K. (1965). Individualized whistle contours in bottlenose dolphins, Tursiops truncatus. Nature, 207, 434-435.

Caldwell, M. C., Caldwell, D. K., \& Tyack, P. L. (1990). Review of the signature-whistle hypothesis for the Atlantic bottlenose dolphin. In S. Leatherwood \& R. R. Reeves (Eds.), The bottlenose dolphin (pp. 199-234). San Diego: Academic Press. 653 pp.

Charif, R. A., Mitchell, S. G., \& Clark, C. W. (1995). Canary 1.2.4 user's manual. Ithaca, NY: Cornell Laboratory of Ornithology. 229 pp.

Cook, M. L. H., Sayigh, L. S., Blum, J. E., \& Wells, R. S. (2004). Signature-whistle production in undisturbed free-ranging bottlenose dolphin (Tursiops truncatus). Proceedings of the Royal Society of London, Series B, Biological Sciences, 271(1543), 1043-1049.

dos Santos, M. E., \& Almada, V. C. (2004). A case for passive sonar: Analysis of click train production patterns by bottlenose dolphins. In J. A. Thomas, C. Moss, \& M. Vater (Eds.), Echolocation in bats and dolphins (pp. 400-403). Chicago: University of Chicago Press. 604 pp.

dos Santos, M. E., \& Lacerda, M. (1987). Preliminary observations of the bottlenose dolphin (Tursiops truncatus) in the Sado Estuary (Portugal). Aquatic Mammals, 13, 65-80.

dos Santos, M. E., Ferreira, A. J., \& Harzen, S. (1995). Rhythmic sound sequences emitted by aroused bottlenose dolphins in the Sado Estuary, Portugal. In P. G. H. Evans \& H. Nice (Eds.), Sensory systems of aquatic mammals (pp. 325-334). Woerden, Netherlands: De Spil Publishers. 588 pp.

dos Santos, M. E., Nunes, S., \& Carvalho, I. (2001). Tracking movements and classifying behaviours of bottlenose dolphins in an estuarine environment. The Fourteenth Biennial Conference on the Biology of Marine Mammals. Vancouver, Canada.

dos Santos, M. E., Caporin, G., Moreira, H. O., Ferreira, A. J., \& Bento-Coelho, J. L. (1990). Acoustic behaviour in a local population of bottlenose dolphins. In J. A. Thomas \& R. A. Kastelein (Eds.), Sensory abilities of cetaceans: Laboratory and field evidence (pp. 585-598). New York: Plenum Press. 710 pp.

dos Santos, M. E., Ferreira, A. J., Ramos, J., Ferreira, J. F., \& Bento-Coelho, J. L. (1996). The acoustic world of the bottlenose dolphins in the Sado estuary. European Research on Cetaceans - 9 (pp. 62-64). Proceedings of the Ninth Annual Conference of the European Cetacean Society. Lugano, Switzerland.
Ferreira, A., Bento-Coelho, J. L., \& dos Santos, M. E. (1996). Underwater noise in the Sado Estuary. AcusticaActa Acustica, 82, S255.

Fripp, D., Owen, C., Quintana-Rizzo, E., Shapiro, A., Buckstaff, K., Jankowski, K., Wells, R. S., \& Tyack, P. (2005). Bottlenose dolphin (Tursiops truncatus) calves appear to model their signature whistles on the signature whistles of community members. Animal Cognition, 8, 17-26.

Gaspar, R. (2003). Status of the resident bottlenose dolphin population in the Sado Estuary: Past, present and future. Ph.D. thesis, St. Andrews University. 213 pp.

Harzen, S. (1998). Habitat use by the bottlenose dolphin (Tursiops truncatus) in the Sado Estuary, Portugal. Aquatic Mammals, 24, 117-128.

Harzen, S. (2002). Use of an electronic theodolite in the study of movements of the bottlenose dolphin (Tursiops truncatus) in the Sado Estuary, Portugal. Aquatic Mammals, 28, 251-260.

Herman, L. M., \& Tavolga, W. N. (1980). The communication systems of cetaceans. In L. M. Herman (Ed.), Cetacean behaviour: Mechanisms and functions (pp 149-209). New York: John Wiley and Sons. 480 pp.

Janik, V. M. (1999). Pitfalls in the categorization of behaviour: A comparison of dolphin whistle classification methods. Animal Behaviour, 57, 133-143.

Janik, V. M. (2000). Whistle matching in wild bottlenose dolphins (Tursiops truncatus). Science, 289, 13551357.

Janik, V. M., \& Slater, P. J. B. (1998). Context-specific use suggests that bottlenose dolphin signature whistles are cohesion calls. Animal Behaviour, 56, 829-838.

Janik, V. M., Dehnhardt, G., \& Todt, D. (1994). Signature whistle variations in a bottlenosed dolphin, Tursiops truncatus. Behavioural Ecology and Sociobiology, 35, 243-248.

Jones, G. J., \& Sayigh, L. S. (2002). Geographic variation in rates of vocal production of free-ranging bottlenose dolphins. Marine Mammal Science, 18, 374-393.

Mann, J. (1999). Behavioral sampling methods for cetaceans: A review and critique. Marine Mammal Science, $15,102-122$.

McCowan, B., \& Reiss, D. (1995). Quantitative comparison of whistle repertoire from captive adult bottlenose dolphins (Delphinidae, Tursiops truncatus): A re-evaluation of the signature whistle hypothesis. Ethology, 100, 194-209.

Ong, L. (1996). The description and analysis of bottlenose dolphin (Tursiops truncatus) whistles. Graduation thesis, National University of Singapore. 58 pp.

Popper, A. N. (1980). Sound emission and detection by delphinids. In L. M. Herman (Ed.), Cetacean behaviour: Mechanisms and functions (pp. 1-52). New York: John Wiley and Sons. $480 \mathrm{pp}$.

Sayigh, L. S., Tyack, P. L., Wells, R. S., \& Scott, M. D. (1990). Signature whistles of free-ranging bottlenose dolphins Tursiops truncatus: Stability and motheroffspring comparisons. Behavioural Ecology and Sociobiology, 26, 247-260. 
Sayigh, L. S., Tyack, P. L., Wells, R. S., Solows, A. R., Scott, M. D., \& Irvine, A. B. (1998). Individual recognition in wild bottlenose dolphins: A field test using playback experiments. Animal Behaviour, 57, 41-50.

Smolker, R., \& Pepper, J. W. (1999). Whistle convergence among allied male bottlenose dolphins (Delphinidae, Tursiops sp.). Ethology, 105, 595-617.

SPSS, Inc. (2001). SPSS 11.0.0. Chicago: Author.

Steiner, W. W. (1981). Species-specific differences in pure tonal whistle vocalizations of five Western North Atlantic dolphin species. Behavioural Ecology and Sociobiology, 9, 241-246.

Tyack, P. L. (1986). Whistle repertoires of two bottlenosed dolphins, Tursiops truncatus: Mimicry of signature whistles? Behavioural Ecology and Sociobiology, 18, 251-257.

Tyack, P. L. (1997). Development and social functions of signature whistles in bottlenose dolphins Tursiops truncatus. Bioacoustics, 8, 21-46.

Wang, D., Würsig, B., \& Evans, W. E. (1995). Whistles of bottlenose dolphins: Comparisons among populations. Aquatic Mammals, 21, 65-77.

Wood, F. G., Jr. (1953). Underwater sound production and concurrent behaviour of captive porpoises, Tursiops truncatus and Stenella plagiodon. Bulletin of Marine Science of the Gulf and Caribbean, 3, 120-133.

Zar, J. H. (1996). Biostatistical analysis. Hertfordshire: Prentice Hall International Ltd. 662 pp. 